localization and removal of the tumour, but there must be some limit to the time allowed for clinical observation, and experience shows that the number of cases in which the growth is not only localizable but operable is very small. The real benefits of decompression are available for a much larger proportion of the cases, and if this procedure is delayed in the hope of receiving greater benefit, disappointment will be the rule rather than the exception, and the moment favourable for decompression will pass." With these words we think a large proportion of our readers will agree. Further, they constitute at least some sort of reply to the questions asked by the surgeon.

\title{
Ophthalmic Benefit
}

From some questions which were recently asked in the House of Commons, a brief report of which appeared in the British Medical Journal of March 6, 1926, it appears that some panel practitioners refer a much higher proportion of their cases for ophthalmic treatment than do others. Any ophthalmic surgeon to a general hospital serving a London district could have told the authorities that this would be the case. The questioner seemed to think that more uniformity could be obtained by orders from headquarters; so it could, but it would be most unjust to attempt anything of the sort. It would be manifestly unfair to limit the number of cases on a panel that the practitioner couid refer for ophthalmic benefit. Suppose for a moment that a panel of 1,000 were allowed only 5 per cent. of the whole to be sent for ophthalmic treatment in any one year, and that the fifty-first applicant was suffering from some serious eye disease; the latter would, it seems to us, have a good case in law against the limiting body, if he or she had to wait a year or even a week for advice and treatment. Flagitio additis damnum.

One way in which to obtain more uniformity would be to require the ophthalmic surgeon when giving his prescription, or when submitting his account to the approved societies, to furnish a certificate that of the cases seen so many were legitimate cases to have been sent for ophthalmic benefit, and so many were not; but this would lead to endless trouble, as some people take a much broader outlook than others. The enthusiast who considers that every headache is ocular in origin and who sees in the correction of a small amount of astigmatism a cure for conditions ranging from dyspepsia to miners' nystagmus is perfectly at liberty to have his own opinions and to send every patient on his panel for ophthalmic benefit ; while the approved societies could hardly take it upon themselves to refuse benefit, as no one could take an affidavit to the effect that the wearing of glasses might not possibly improve a patient's general health and so lead to an improvement 
in the local condition for which the patient applied in the first place; but now that the ophthalmic benefit is beginning to be placed on a proper basis, it is probable that the panel doctor will make more effort to determine whether the patient's symptoms are or are not due to errors of refraction. The case of offenders in this respect will no doubt be investigated by the Ministry of Health, but we are not aware that any competent authority has been appointed by this body to investigate such cases.

There is another aspect of the ophthalmic benefit which has not yet been investigated and that is, what is to be done with the panel patients when they attend ophthalmic hospitals? Is it the duty of the hospital to refer these patients back to their panel practitioner for a recommendation to see an ophthalmic surgeon, or should they be treated at the hospital in the ordinary way?

In some instances patients bring their society's ophthalmic benefit letters to the hospital. The fees which are payable to an ophthalmic surgeon on the filling up of this letter are not payable to hospital authorities and the cases should be referred to an ophthalmic surgeon on the ophthalmic panel. Many of the letters issued by the approved societies have no place for the signature or certificate of an. ophthalmic surgeon, which is evidently a mistake on their part, as otherwise they do not know to whom the fee for examination should be paid. Sufficient time has not elapsed for the working of the benefit to settle down, but information on the points referred to above and others which may arise would be of considerable service in determining how the benefit is working all over the country.

We understand that a sub-committee has been appointed by the Council of British Ophthalmologists to inquire into the subject; information from our readers would be of considerable service and should be sent to the Hon. Secretary of the Council of British Ophthalmologists, 86, Brook Street, London, W.1.

\section{DEPUTATION FROM THE JOINT COUNCIL OF QUALIFIED OPTICIANS AND THE BRITISH OPTICAL ASSOCIATION TO THE MINISTRY OF HEALTH}

The Minister of Health, the Rt. Hon. Neville Chamberlain, received on March 26 a deputation from the Joint Council of Qualified Opticians, with which was associated the British Optical Association, to discuss a Bill to secure the registration of Optical Practitioners and to regulate the practice of sight testing and optical dispensing, which had been presented to Parliament by a Private Member. The deputation was introduced by Mr. S. P. Viant, M. P. 